\title{
EXTRAÇÃO DE ÓLEO DE GERGELIM PROVENIENTE DE TORTA RESIDUAL DA PRENSAGEM UTILIZANDO-SE SOLVENTES ALCOÓLICOS
}

\author{
M. C. CAPELLINI ${ }^{1}$, V. GIACOMINI ${ }^{1}$ e C. E. C. RODRIGUES ${ }^{1}$ \\ ${ }^{1}$ Universidade de São Paulo, Faculdade de Zootecnia e Engenharia de Alimentos, Departamento de \\ Engenharia de Alimentos \\ E-mail para contato: chrisrodrigues@usp.br
}

\begin{abstract}
RESUMO - A semente de gergelim destaca-se pelo alto conteúdo de óleo e proteína presentes em sua matriz sólida e pela elevada atividade antioxidante de seu extrato devido, principalmente, à sesamina. Após a prensagem das sementes, a torta residual pode conter, ainda, de 18 a $22 \%$ de óleo. Com o objetivo de aumentar o rendimento da extração de óleo e valorizar o material desengordurado, este trabalho avaliou a influência das variáveis do processo de extração com solventes alcoólicos na qualidade dos produtos obtidos. Realizaram-se experimentos de extração sólido-líquido na condição de equilíbrio, contactando-se a torta de semente de gergelim com o solvente etanol em grau absoluto ou azeotrópico, nas temperaturas de 50 a $80{ }^{\circ} \mathrm{C}$, mantendo-se constante a razão farelo:solvente em 1:3. Os resultados mostraram que a hidratação do solvente etanólico influencia negativamente o rendimento da extração de óleo, enquanto o aumento da temperatura favorece este processo. Quanto ao teor proteico da fase rafinado, observou-se que este é sempre superior ao conteúdo presente inicialmente na torta, resultado relacionado à extração de óleo da matriz sólida, ou seja, quanto maior quantidade de óleo transferido para a fase extrato, maior a concentração de proteína na fase rafinado correspondente.
\end{abstract}

\section{INTRODUÇÃO}

Acredita-se que o gergelim (Sesamum indicum L.) é uma das culturas mais antigas cultivadas pelos seres humanos e atualmente constitui uma das mais importantes culturas oleaginosas da América Central, África Tropical e Ásia Oriental, com produção global ultrapassando 4 milhões de toneladas, segundo Achouri et al. (2012).

A semente de gergelim contém mais óleo do que as principais oleaginosas, tais como soja, canola, girassol e algodão. O conteúdo em óleo varia de acordo com a variedade, origem, cor e tamanho da semente. Em geral, as sementes cultivadas para extração contêm cerca de 50\% de óleo, segundo Hwang (2005), enquanto o teor de proteína está em torno de $25 \%$. Contém, ainda, cerca de $5 \%$ de cinzas e variado conteúdo de fibras e carboidratos (de 3,4 a 12,5\%). O óleo de gergelim apresenta menos de $20 \%$ de ácidos graxos saturados sendo eles, principalmente, o ácido palmítico (7,9 a 12\%) e o ácido esteárico (4,8 a 6,1\%). Por sua vez, os ácidos graxos insaturados oleico e 


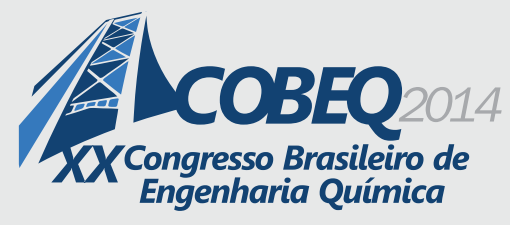

19 a 22 de outubro de 2014
Florianópolis/SC

linoleico constituem mais de $80 \%$ em quantidades que variam de 35,9 a $42,3 \%$ e 41,5 a $47,9 \%$ de oleico e linoleico, respectivamente (Hwang, 2005).

Em comparação com outros óleos vegetais, o óleo de gergelim possui conteúdo relativamente alto de material insaponificável, aproximadamente 2\%. Este inclui esteróis, álcoois triterpênicos, tocoferóis e lignanas (Hwang, 2005). A presença de lignanas, antioxidantes naturais, está relacionada tanto à estabilidade oxidativa superior deste óleo, apesar dos níveis elevados de ácidos graxos insaturados, quanto aos efeitos fisiológicos benéficos do gergelim. Nas sementes de gergelim cruas, sesamina e sesamolina são as duas lignanas principais (Hwang, 2005; Lee et al., 2010). Segundo Bhatnagar et al. (2013), a semente contém 0,4\% de sesamina e 0,3\% de sesamolina.

De acordo com Hwang (2005), a torta resultante da extração por prensagem de óleo de gergelim com casca ainda pode conter de 18 a $22 \%$ de óleo residual. Muitas vezes esta quantidade de óleo é extraída com um solvente ou pressionada novamente para obtenção de mais óleo, aumentando, assim, o rendimento da produção. Após a retirada do óleo, as sementes de gergelim parcialmente desengorduradas contêm proteína de alta qualidade adequada ao consumo humano, podendo ser utilizada como ingrediente em alimentos funcionais e suplementos nutricionais.

A maioria das proteínas presentes na semente de gergelim são proteínas de armazenamento e constituídas de globulinas $(67,3 \%)$, albuminas $(8,6 \%)$, prolaminas $(1,4 \%)$, e glutelinas $(6,9 \%)$, segundo Achouri et al. (2012). A proteína do gergelim é rica em lisina $(3,1 \%)$ e, também, rica em aminoácidos sulfurados metionina e cistina $(6,1 \%)$ que são, muitas vezes, aminoácidos limitantes em leguminosas. A fração proteica do gergelim está, no entanto, no limite de deficiência de outros aminoácidos essenciais, tais como a valina, treonina e isoleucina, porém contém uma quantidade adequada de triptofano, que é limitado em muitas proteínas de sementes oleaginosas. Devido à sua composição de aminoácidos, a fração proteica da semente de gergelim é considerada como uma excelente fonte complementar de proteínas vegetais tais como a soja e o amendoim, aumentando, assim, seu valor nutricional (Hwang, 2005).

No que diz respeito a extração de óleos vegetais, o solvente tradicionalmente empregado é uma mistura de isômeros de hexano, derivados do petróleo, denominado industrialmente como hexana. Apesar de sua maior estabilidade e maior capacidade de extração de óleo do material oleaginoso, este solvente é altamente tóxico e inflamável, além de apresentar origem fóssil (Johnson e Lusas, 1983; Anderson, 2005; Hammond et al., 2005; Tir et al., 2012). Neste sentido, segundo Tir et al. (2012), a procura por solventes alternativos seguros e capazes de produzir óleo e farelo desengordurado de boa qualidade tem gerado esforços por parte dos pesquisadores. Dentre estes, destacam-se os álcoois de cadeia curta, especialmente o etanol e o isopropanol. Em função de sua maior polaridade, estes solventes são capazes de extrair maior quantidade de material insaponificável da matriz sólida (Nagendra Prasad et al., 2011) e, adicionalmente, estes solventes alcoólicos podem ser parcialmente retirados do extrato apenas com o abaixamento da temperatura em razão de sua miscibilidade parcial com o óleo (Johnson e Lusas, 1983).

Com base no exposto, propõe-se a utilização de solventes alcoólicos alternativos na extração do óleo residual contido na torta de semente de gergelim, de maneira a aumentar o rendimento da 
extração e valorizar o material desengordurado, avaliando os impactos causados por esta substituição na qualidade do óleo obtido.

\section{MATERIAIS E MÉTODOS}

\subsection{Materiais}

A torta de semente de gergelim foi gentilmente cedida pela empresa Pazze (Panambi, RS, Brasil). Como reagentes foram utilizados etanol absoluto (Merck, min. 99,8\%), etanol azeotrópico preparado a partir da diluição do etanol absoluto com água deionizada $(6,24 \pm 0,49, \%$ em massa).

\subsection{Métodos Experimentais}

Inicialmente, a matéria-prima, torta de semente de gergelim, foi caracterizada em termos de umidade (Ac 2-41, AOCS, 1998), teor de lipídeos utilizando-se um sistema de extração com solvente à alta temperatura (método Am 5-04, AOCS, 1998) e teor de nitrogênio total (Ba 4f-00, AOCS, 1998). Para conversão do teor de nitrogênio total em proteína, este foi multiplicado pelo fator 6,25 (AOAC, 2007).

Para a execução dos experimentos de extração de óleo das matrizes sólidas foi utilizado um extrator (Marconi, modelo MA-483/EC2) construído em aço inoxidável e vedado hermeticamente, o que evita perdas de massa por evaporação. Os sistemas sólido-líquido foram obtidos adicionando-se massa conhecida da matéria-prima e contactando-a com massa conhecida de solvente alcoólico, etanol em grau absoluto ou azeotrópico, mantendo a proporção farelo:solvente em 1:3. O extrator foi submetido à agitação constante de $175 \mathrm{rpm}$ até a temperatura atingir o valor desejado e mantido sob esta velocidade constante de agitação por mais uma hora. Vale ressaltar que as condições de razão sólido:solvente e agitação estão baseadas em trabalhos prévios desenvolvidos no Laboratório de Engenharia de Separações (Oliveira et al., 2012; Rodrigues et al., 2010).

Após este tratamento, amostras da fase extrato foram retiradas pela válvula localizada na parte inferior do extrator e submetidas às análises de teor de água pelo método oficial de titulação Karl Fischer Ca 2e-84 (AOCS, 1998), concentração de solvente por evaporação em estufa de convecção forçada (Nova Orgânica, modelo N035/3) a temperatura de $60^{\circ} \mathrm{C}$ durante 24 horas e teor de proteínas de acordo com o método oficial AOCS Ba 4f-00 (1998), utilizando-se o determinador de proteína Leco (modelo FP-528), calibrado com 150 mg de padrão EDTA (Leco). A quantidade de proteína foi determinada multiplicando-se o teor de nitrogênio pelo fator 6,25 (AOAC, 2007). A fase rafinado foi submetida à pesagem, em balança semi-analítica para determinação do teor de solução aderida às fibras (índice de retenção) e, também, submetida às análises de concentração de solvente e teor de nitrogênio para o cálculo da quantidade de proteínas, utilizando-se os mesmo equipamentos e métodos supracitados. 


\section{9 a 22 de outubro de 2014 \\ Florianópolis/SC}

\section{RESULTADOS E DISCUSSÃO}

O resíduo da extração de óleo, por meio de prensagem, da semente de gergelim, matéria-prima utilizada neste trabalho, contém em sua composição cerca de $(7,95 \pm 0,08) \%$ de umidade, $(19,54 \pm$ $1,36) \%$ de óleo e $(41,60 \pm 0,30) \%$ de proteína. De maneira geral, o teor de óleo residual da torta de semente de gergelim está de acordo com dados observados na literatura (Hwang, 2005).

Os resultados de extração de compostos lipídicos, obtidos em fração mássica destes nas fases extrato e rafinado, foram expressos em termos de rendimento, ou seja, quantidade de compostos lipídicos extraídos pelo total de óleo contido na torta de semente de gergelim seca. Desta maneira, o rendimento de extração de óleo de torta de semente de gergelim, utilizando-se como solventes etanol em grau absoluto e azeotrópico, nas temperaturas de 50 a $80{ }^{\circ} \mathrm{C}$, é apresentado na Figura 1.

Observa-se que o solvente etanol em grau absoluto apresenta maior capacidade de extração de componentes lipídicos, ultrapassando $90 \%$ de extração do óleo total contido na matriz sólida, em um estágio, à temperatura de $80{ }^{\circ} \mathrm{C}$, quando comparado ao solvente etanol azeotrópico. Com base nos resultados apresentados na Figura 1 pode-se inferir que o aumento do grau de hidratação do solvente etanólico influencia negativamente a extração dos componentes lipídicos da torta de semente de gergelim. Por outro lado, com o aumento da temperatura do processo, observa-se um aumento no rendimento da extração, independente do solvente utilizado.

Rao et al. (1955) determinaram valores para a solubilidade de óleo de gergelim em solventes etanólicos contendo 0, 2 e 4,6\% de água. Nestes casos, as temperaturas nas quais a solubilidade do óleo no solvente é máxima, chamadas de temperaturas críticas, foram cerca de 65,70 e $90{ }^{\circ} \mathrm{C}$, respectivamente. No caso da torta de semente de gergelim utilizada neste trabalho, conforme os dados apresentados na Figura 1, na faixa de temperatura de 60 a $80^{\circ} \mathrm{C}$, para o etanol absoluto, verificou-se, em média, $85 \%$ do óleo se transferiu para a fase extrato. No caso do solvente etanol em grau azeotrópico, contendo $6 \%$ de água, nesta mesma faixa de temperatura de processo, a solubilidade do óleo no solvente é de cerca de $80 \%$.

A influência da polaridade do solvente utilizado na extração de óleo de semente de gergelim foi avaliada no trabalho de Tir et al. (2012). Óleo de 50 gramas de semente de gergelim secas e prensadas foi extraído pelo método Soxhlet utilizando-se diversos solventes orgânicos (hexano, etanol, acetona, diclorometano, isopropanol) e misturas de hexano:isopropanol e clorofórmio:metanol, durante 12 horas. Os autores relataram que o rendimento de extração do óleo depende significativamente do solvente utilizado e, neste caso, a constante dielétrica (que é uma medida da polaridade do solvente) é o parâmetro chave na determinação das interações soluto:solvente. Observou-se que os solventes que apresentam constante dielétrica entre 6 e 8, como o diclorometano e a mistura hexano:isopropanol, mostraram maior rendimento de extração do que aqueles com menores ou maiores constantes dielétricas, sendo estes de, aproximadamente, 56 e 48\%, respectivamente. Para o solvente etanol, o rendimento de extração de óleo foi de cerca de $30 \%$ e para o hexano, solvente comumente utilizado na extração de óleos vegetais, de $44 \%$, aproximadamente. 


\section{9 a 22 de outubro de 2014 \\ Florianópolis/SC}

Desta forma, pode-se inferir que o aumento do grau de hidratação do solvente diminui a solubilidade do óleo neste solvente e, por outro lado, o aumento da temperatura do processo de extração acarreta em um aumento da solubilidade do óleo, independentemente do solvente utilizado.

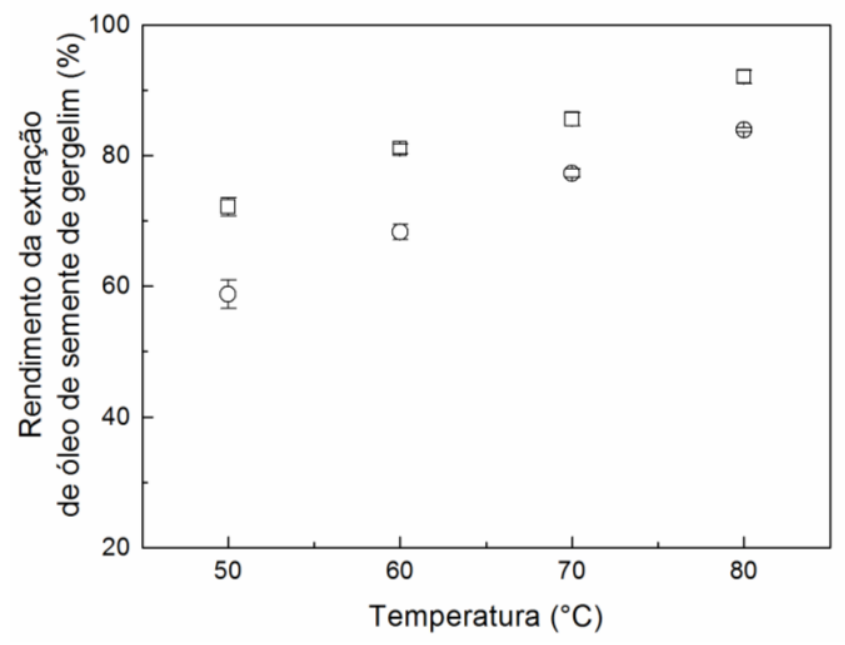

Figura 1 - Rendimento da extração de óleo de gergelim (\%) em função da temperatura de processo: ( $\square$ ) etanol com $0 \%$ de água, em massa (o) etanol com $6 \%$ de água, em massa.

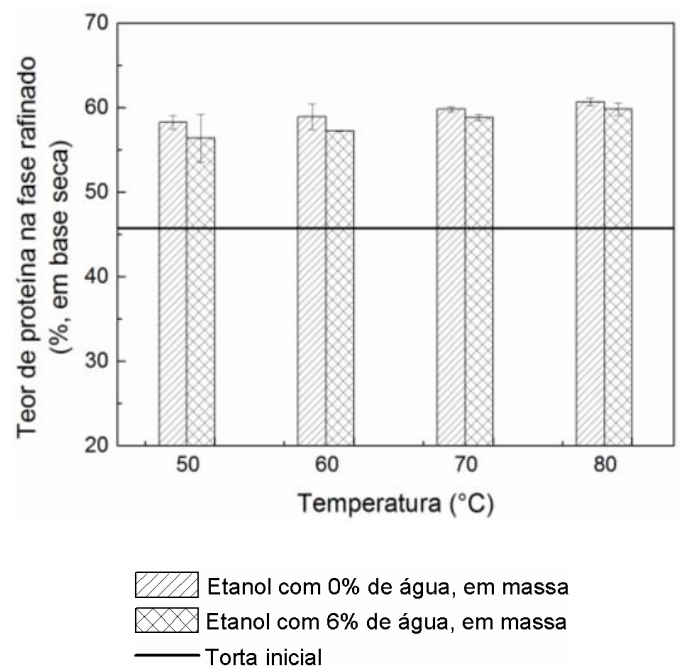

Figura 2 - Teor de proteína da fase rafinado comparada ao teor de proteína da matéria-prima $(45,71 \pm 0,7 \%$, em base seca), em função da temperatura de processo.

Na Figura 2 são apresentados os teores de proteína contidos na torta de semente de gergelim antes desta ser submetida ao processo de extração de óleo utilizando-se solventes (torta inicial) e da torta desengordurada, fase rafinado, ou seja, após o processo de extração com solventes, nas temperaturas de 50 a $80{ }^{\circ} \mathrm{C}$ e utilizando-se etanol em grau absoluto e azeotrópico.

De maneira geral, pode-se dizer que os teores de proteína na fase rafinado são significativamente superiores ao teor de proteína presente na matriz sólida que ainda não foi submetida ao processo de extração, independente da condição de processo. Este teor superior está relacionado à extração do óleo do material, ou seja, quanto maior a quantidade de óleo retirado da torta de semente de gergelim, maior será a concentração de proteína na fase rafinado proveniente do processo de extração. Neste sentido, observa-se que o teor de proteína na fase rafinado quando emprega-se etanol absoluto é maior do que este teor quando etanol contendo $6 \%$ de água é utilizado na extração do óleo da torta de semente de gergelim, uma vez que o emprego do solvente em grau absoluto resulta em maiores valores de rendimento da extração de compostos lipídicos (Figura 1).

Neste trabalho, para a fase rafinado, foi realizada também a determinação do índice de retenção que é dado pelo teor de solução extrato aderido à massa de sólidos inertes e expresso em kg de solução aderida por kg de sólidos inertes. Na Figura 3 são apresentados os valores de índice de retenção para as extrações utilizando-se etanol em grau absoluto e azeotrópico como solventes e temperaturas de 50 a $80{ }^{\circ} \mathrm{C}$. 
De acordo com o trabalho publicado por Rodrigues e Oliveira (2010), o índice de retenção é uma variável que exerce grande influência no número de estágios de contato necessários para a extração de óleos vegetais, no projeto de extratores. Este fato impactará no volume do extrator e, em adição, na etapa posterior de dessolventização da matriz sólida desengordurada.

Observa-se um aumento dos valores de índice de retenção quando utiliza-se o solvente etanólico mais hidratado no processo de extração de óleo, para uma mesma temperatura de processo. Por outro lado, quando há um aumento na temperatura de extração, verifica-se a diminuição nos valores de índice de retenção. Segundo Kocatas e Cornell (1954), o índice de retenção pode ser relacionado com as propriedades físicas (densidade e viscosidade) da solução extrato e, desta maneira, extratos mais viscosos ocasionarão maiores índices de retenção e menores taxas de extração. Sendo assim, um maior número de estágios teóricos será necessário ao extrator para exaurir completamente a matriz oleaginosa (Wisniak et al., 1987).

No presente estudo, verifica-se que a redução dos valores de índice de retenção pode estar associada à diminuição da viscosidade da fase extrato quando há o aumento da temperatura do processo de extração, independente do solvente utilizado neste processo. De acordo com o trabalho publicado por Zhang et al. (2002), que estudaram a eficiência do álcool isopropílico na extração de óleo de algodão, a retenção tende a aumentar quando há diminuição do conteúdo de óleo residual na matriz sólida, ou seja, o índice de retenção aumenta quando a viscosidade da fase extrato aumenta.

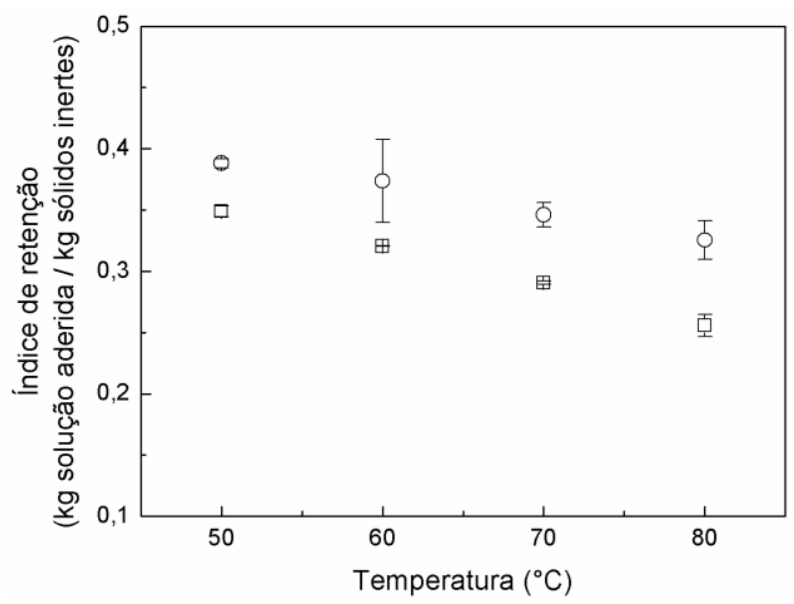

Figura 3 - Índice de retenção em função da temperatura de processo: ( $\square$ ) etanol com 0\% de água, em massa; ( $)$ etanol com $6 \%$ de água, em massa.

Rittner (1992) comparou os valores de índice de retenção para o solvente etanol em relação ao hexano, no processo de extração de óleo de soja. Os valores de retenção reportados para o solvente etanol foram maiores do que os obtidos para o solvente hexano. Neste caso, a grande atração entre o solvente alcoólico, polar, e a matriz sólida, foi considerada como responsável por estes resultados. De maneira geral, os valores de retenção no presente estudo variaram de 0,25 a $0,35 \mathrm{~kg}$ de solução aderida / $\mathrm{kg}$ de sólidos inertes quando utilizou-se etanol em grau absoluto e de 0,32 a 0,39 $\mathrm{kg}$ de solução 


\section{9 a 22 de outubro de 2014 \\ Florianópolis/SC}

aderida / kg de sólidos inertes quando utilizou-se etanol em grau azeotrópico. Estes valores estão próximos dos valores reportados na extração do óleo de soja em pellets utilizando-se hexano $(0,39 \mathrm{~kg}$ de solução aderida / $\mathrm{kg}$ de sólidos inertes) e para o etanol em grau azeotrópico $(0,43 \mathrm{~kg}$ de solução aderida / kg de sólidos inertes) como solventes (RITTNER, 1992). No trabalho de Capellini (2013), no qual óleo de farelo de arroz em pellets foi extraído utilizando-se etanol, contendo 0 e $6 \%$ de água em sua composição, como solvente e temperaturas de 50 a $80{ }^{\circ} \mathrm{C}$, foram obtidos valores de índice de retenção que variaram de 0,44 a $0,48 \mathrm{~kg}$ de solução aderida / $\mathrm{kg}$ de sólidos inertes para etanol absoluto e 0,55 a 0,57 kg de solução aderida / kg de sólidos inertes para etanol azeotrópico.

\section{CONCLUSÕES}

A partir dos resultados obtidos neste trabalho, para os experimentos de extração de óleo residual presente na torta de semente de gergelim, utilizando-se etanol como solvente, pode-se inferir que, de maneira geral, a hidratação do solvente exerce forte influência no sentido de suprimir a transferência de compostos lipídicos da matriz sólida para a fase extrato. O aumento do teor de água no solvente etanólico, de 0 para $6 \%$ de água, ocasionou uma diminuição na quantidade de óleo extraído. Por outro lado, o aumento da temperatura do processo favoreceu a extração.

Em vista aos resultados obtidos, pode-se dizer que a substituição da hexana, comumente utilizada no processo de extração de óleos vegetais, pelo solvente alternativo, etanol, apresenta viabilidade técnica. No entanto, novos experimentos deverão ser realizados de maneira que outras variáveis que influenciam diretamente a qualidade do óleo e farelo desengordurado e condições sob as quais o processo de extração será realizado possam ser cuidadosamente avaliadas para que seja possível a obtenção de produtos adequados às aplicações alimentícias.

\section{AGRADECIMENTOS}

As autoras agradecem à FAPESP (Fundação de Amparo à Pesquisa do Estado de São Paulo, processo $n^{\circ}$ 2013/13339-6) e PIBIC-CNPq (Conselho Nacional de Desenvolvimento Científico e Tecnológico) pelo apoio financeiro concedido.

\section{REFERÊNCIAS}

A.O.A.C. Official methods of analysis. 18th ed. Washington, D. C.: A.O.A.C., 2007. 1051 p.

A.O.C.S. Official methods and recommended practices of the American Oil Chemists' Society. Press, 3rd ed. Champaign, v.1-2, 1998.

ACHOURI, A.; NAIL, V.; BOYE, J. I. Sesame protein isolate: Fractionation, secondary structure and functional properties. Food Res. Int., v. 46, p. 360-369, 2012.

ANDERSON, D. A Primer on Oils Processing Technology In: SHAHIDI, F. (Ed.) Bailey's Industrial Oil and Fat Products. 6th ed., v.5, Cap. 1, p.1-56, New Jersey: John Wiley and Sons, 2005.

BHATNAGAR, A. S.; HEMAVATHY, J.; GOPALA KRISHNA, A. G. Development of a rapid method for determination of lignans content in sesame oil. J. Food Sci. Tech., 2013. 
CAPELlini, M. C. Extração de Óleo de Farelo de Arroz utilizando Solventes Alcoólicos: Avaliação de Alterações na Fração Proteica e na Composição do Óleo. Dissertação de Mestrado. Universidade de São Paulo, Faculdade de Zootecnia e Engenharia de Alimentos. Pirassununga, 2013.

HAMMOND, E. G.; JOHNSON, L. A.; SU, C.; WANG, T.; WHITE, P. J. Soybean Oil. In: SHAHIDI, F. (Ed.) Bailey's Industrial Oil and Fat Products. 6th ed., v.2, Cap. 13, p.577-650. New Jersey: John Wiley and Sons, 2005.

HWANG, L. S. Sesame Oil In: SHAHIDI, F. (Ed.) Bailey's Industrial Oil and Fat Products. 6th ed., v.2, Cap. 12, p.537-576. New Jersey: John Wiley and Sons, 2005.

JOHNSON, L. A.; LUSAS, E. W. Comparison of alternative solvents for oils extraction. J. Am. Oil Chem. Soc., v. 60, n. 2, p. 229-242, 1983.

KOCATAS, B. M.; CORNELL, D. Holdup and residual saturation of hexane in gravity-drained soybean flake beds. Ind. Eng. Chem., v. 46, p. 1219-1224, 1954.

LEE, S. W.; JEUNG, M. K.; PARK, M. H.; LEE, S. Y.; LEE, J. H. Effects of roasting conditions of sesame seeds on the oxidative stability of pressed oil during thermal oxidation. Food Chem., v. 118, p. 681-685, 2010.

NAGENDRA PRASAD, M. N.; SANJAY, K. R.; SHRAVYA KHATOKAR, M.; VISMAYA, M. N.; NANJUNDA SWAMY, S. Health Benefits of Rice Bran - A Review. J. Nutr. Food Sci., v. 3, 2011.

OLIVEIRA, R.; OLIVEIRA, V.; ARACAVA, K. K.; RODRIGUES, C. E. C. Effects of the extraction conditions on the yield and composition of rice bran oil extracted with ethanol - A response surface approach. Food Bioprod. Process., v. 90, p. 22-31, 2012.

RAO, R. K.; KRISHNA, M. G.; ZAHEER, S. H.; ARNOLD, L. K. Alcoholic extraction of vegetable oils. I. Solubilities of cottonseed, peanut, sesame, and soybean oils in aqueous ethanol. J. Am. Oil Chem. Soc., v. 32, p. 420-423, 1955.

RITTNER, H. Extraction of vegetable oils with ethyl alcohol. Oléagineux, v. 47, n.1, p. 29, 1992.

RODRIGUES, C. E. C.; ARACAVA, K. K.; ABREU, F. N. Thermodynamic and statistical analysis of soybean oil extraction process using renewable solvent. Int. J. Food Sci. Tech., v. 45, p. 2407-2414, 2010.

RODRIGUES, C. E. C.; OLIVEIRA, R. Response surface methodology applied to the analysis of rice bran oil extraction process with ethanol. Int. J. Food Sci. Tech., v. 45, p. 813-820, 2010.

TIR, R.; DUTTA, P. C.; BADJAH-HADJ-AHMED, A. Y. Effect of the extraction solvent polarity on the sesame seeds oil composition. Eur. J. Lipid Sci. Tech., v. 114, p. 1427-1438, 2012.

WISNIAK, J.; HILLET, J., KATZ O. Holdup and Extraction Characteristics of Jojoba Meal. J. Am. Oil Chem. Soc., v. 64, p. 1352-1354, 1987.

ZHANG, F.; RHEE, K. C.; KOSEOGLU, S. S. Isopropyl alcohol extraction of cottonseed collets: efficiency and performance. J. Food Lipids, v.9, p.147-160, 2002. 